\title{
Development of Low-Magnetic-Permeability Welds of 316L Stainless Steel
}

\author{
This study discusses a technique for fabricating ASME-code-compliant stainless \\ steel vacuum chambers and particle accelerator pressure vessels
}

BY A. KUMAR, P. GANESH, V. K. SHARMA, M. MANEKAR, R. K. GUPTA, R. SINGH, M. K. SINGH, G. MUNDRA, AND R. KAUL

\begin{abstract}
Austenitic stainless steel is often used as the construction material for particle accelerator vacuum chambers. It is also a strong candidate construction material for helium vessels of superconducting radiofrequency cavities of highenergy, high-power particle accelerators. One of the major limitations of austenitic stainless steels for their application in particle accelerators is the relatively higher magnetic permeability of its welds. The present paper describes an experimental study to obtain a low-magnetic-permeability gas tungsten arc weld of $316 \mathrm{~L}$ stainless steel while using ER $316 \mathrm{~L}$ stainless steel filler metal through controlled addition of nitrogen in the argon shielding gas. It was demonstrated that $316 \mathrm{~L}$ stainless steel welds, made with the addition of $1.5 \%$ nitrogen in the argon shielding gas, were associated with magnetic permeability close to that of the base metal. The welds exhibited good strength and ductility in addition to qualifying the impact test requirement of the American Society of Mechanical Engineers Boiler \& Pressure Vessel Code (BPVC) for operation at room temperature and liquid helium temperature $(4 \mathrm{~K})$. The technique is important for the fabrication of BPVC-compliant 316L stainless steel vacuum chambers and pressure vessels of particle accelerators, including helium vessels of superconducting radiofrequency cavities.
\end{abstract}

\section{KEYWORDS}

- 316L Stainless Steel • Gas Tungsten Arc Welding

- Magnetic Permeability • Nitrogen Addition

- Shielding Gas • Particle Accelerators

\section{Introduction}

\section{Background}

Magnetic permeability $\left(\mu_{\mathrm{r}}\right)$ is one of the important factors governing the choice of material for construction of vacuum chambers of particle accelerators, particularly those placed near the magnets. $\mu_{\mathrm{r}}$ of the material must be close to one to minimize the distortion of the applied magnetic field. In light of the above-mentioned considerations, the choice of construction material for vacuum chambers of particle accelerators is practically limited to either aluminum, aluminum alloys, or austenitic stainless steels (SSs).

Aluminum and its alloys are often used for the construction of vacuum chambers that are placed near the magnets. Gas tungsten arc welding (GTAW) of conventional aluminum alloys like AA6061, 6063, 5083, and 5086 produces nonmagnetic weld metals, but it requires special skills/care not only during welding but also during storage of weld filler metals and the base metal. The aluminum alloy weld metals are often marked with solidification cracking and porosities (Refs. 1-5). With respect to austenitic SS, aluminum alloy vacuum chambers also suffer from higher material and manufacturing costs, higher wall thicknesses arising from their lower elastic modulus, and higher eddy current losses due to their higher electrical conductivity. Limited availability of qualified welders of aluminum alloys is also a limiting factor toward the fabrication of aluminum alloy vacuum chambers.

Alternatively, austenitic SSs, due to their excellent mechanical properties at cryogenic temperatures and machinability as well as the availability of fabrication vendors, are an attractive choice for the construction of particle accelerator vacuum chambers. Apart from copper-plated, normalconducting cavities, austenitic SS is also a strong candidate material for the construction of helium vessels of superconducting radiofrequency (SRF) cavities of high-energy, highpower particle accelerators. The SRF cavities, made of niobium (Ref. 6), are operated at $2 \mathrm{~K}$. The niobium cavity is housed in a liquid helium bath called "helium vessel." Conventionally, the helium vessel is made of titanium due to the close matching of its coefficient of thermal expansion with niobium ( $\alpha$ Ti: $8.4-8.6 \mu \mathrm{m} / \mathrm{m} . \mathrm{K} ; \alpha \mathrm{Nb}: 7.2-7.3 \mu \mathrm{m} / \mathrm{m}$.K from 273-373 K [Ref. 7]). Titanium helium vessels cannot meet the requirements of the American Society of Mechanical Engineers (ASME) Boiler and Pressure Vessel Code (BPVC) Section VIII, Division 1, (Ref. 8) and pose severe challenges during their welding due to the active nature of the metal. In contrast, helium vessels made of austenitic 316L SS can meet the requirements of Section VIII, Division 1, of the ASME BPVC, and they are also cost effective. 
The most critical factor influencing the performance of the austenitic stainless steel components is their residual $\mu_{r}$, which must be very close to one to minimize the distortion of the magnetic field. In austenitic SS, the two major sources of residual $\mu_{\mathrm{r}}$ are the formation of ferromagnetic strain-induced martensite during forming and machining and $\delta$-ferrite in the weld metal (WM) (Ref. 9). The formation of strain-induced martensite is largely governed by chemical composition. The undesirable effect of strain-induced martensite formation can be effectively suppressed by the following: 1) increasing relative concentrations of strong austenite stabilizers, nitrogen, and carbon, although other alloying elements like $\mathrm{Ni}, \mathrm{Mo}, \mathrm{Cr}$, and $\mathrm{Si}$ also display a relatively lower degree of effects on the suppression of strain-induced martensite formation (Ref. 10), and 2) solution annealing of the formed component. It may be noted that an increase in $C$ content is not a preferred choice as it leads to the problem of weld decay in the heat-affected zone (HAZ) of the weldment (Ref. 11). Alternatively, a small amount of the ferromagnetic $\delta$-ferrite phase is purposely introduced in the room-temperature (RT) microstructure of the austenitic SS WM to suppress weld solidification cracking (Refs. 12, 13).

Many reasons have been proposed that are responsible for enhanced solidification cracking resistance of austenitic SS welds. Some of the important factors are the following: 1) Higher solubility of sulphur (S) and phosphorous (P) in $\delta$ ferrite (than in austenite) leaves little segregation of $S$ and $P$ at the grain boundary region; 2) an irregular crack path offered by a duplex austenite $(\gamma) /$ delta-ferrite $(\delta)$ structure helps in arresting the crack (Ref. 14); 3) lower surface energy of $\gamma / \delta$ leads to reduced wettability by eutectic films as compared to a $\gamma / \gamma$ or $\delta / \delta$ interface (Ref. 15$) ; 4$ ) presence of $\delta$-ferrite results in more interface area, and subsequent solid-state transformation to $\gamma$ results in reduced concentration of impurity elements at grain boundaries; 5 ) greater ductility of $\delta$-ferrite at high temperatures (as compared to the $\gamma$ phase) facilitates stress relaxation; 6) the lower coefficient of thermal expansion of $\delta$-ferrite (with respect to the $\gamma$ phase) leads to reduced shrinkage stress; 7) there is a narrower solidification temperature range for primary ferrite welds (with respect to primary austenite welds) (Ref. 16); 8) the presence of ferrite refines grain size of the solidified WM, resulting in better mechanical properties and cracking resistance; 9) a higher coefficient for impurity diffusion in ferrite (with respect to the $\gamma$ phase) allows faster homogenization in ferrite; and 10) volume contraction associated with $\delta$-ferrite-to- $\gamma$ transformation reduces tensile stresses close to the crack tip (Ref. 17). In this respect, many predictive diagrams have been proposed for predicting RT weld microstructure. These diagrams are extremely useful in identifying the chemical composition of weld filler metals for controlling resultant WM microstructure, which in turn controls solidification cracking. The diagrams developed by Schaffler (Ref. 18), Delong (Refs. 19, 20), and the Welding Research Council (Refs. 21, 22) are some of the most used predictive diagrams.

Because solidification cracking in austenitic SS welds occurs prior to their complete solidification, cracking resistance of the WM is mainly influenced by the sequence of microstructural changes during the course of solidification and is not based on its RT microstructure. Masumoto et al. reported that the primary ferrite mode of solidification is more important than the residual ferrite content after weld- ing in suppressing cracking in austenitic SS welds (Ref. 23). It is now well known that welds made with the primary austenite mode of solidification are relatively more prone to solidification cracking, whereas those that solidify with the ferrite mode exhibit better resistance against solidification cracking (Ref. 24). Control of the primary mode of weld solidification is obtained by controlling the chemical composition of the filler metal. Kujunpaa et al. reported an abrupt increase in cracking propensity in duplex SS WM as its $\mathrm{Cr}_{\text {eq }} / \mathrm{Ni}_{\text {eq }}$ ratio (where $\mathrm{Cr}_{\text {eq }}$ and $\mathrm{Ni}_{\text {eq }}$ are defined in Schaffler's diagram) dropped below 1.5 (Ref. 25). This observed effect is attributed to the change in the primary mode of solidification from ferrite to austenite.

Based on the research carried out to review the role of $\delta$ ferrite in suppressing solidification cracking, it was suggested that a higher Mn content in the WM is an effective means to obtain completely defect-free austenitic welds (Ref. 26). The beneficial effect of $\mathrm{Mn}$ is attributed to the fact that it encourages ferrite solidification at high temperatures, while promoting its rapid transformation to austenite at lower temperatures (Refs. 27, 28). In addition, the high Mn content of austenitic SS welds also serves to tie up S to form highermelting MnS- $\gamma$ eutectic in place of crack-promoting iron/nickel sulphide (Refs. 29-31). Dixon demonstrated that ferrite-free welds of exceptionally low sensitivity to solidification cracking can be obtained with a high-Mn electrode (Fe-20Cr-15Ni7.6Mn-2Mo) (Ref. 31). Kane et al. reported development of a low- $\delta$-ferrite, high-Mn welding consumable for cryogenic applications (4 K) (Ref. 32). Use of these kinds of SS filler metals should result in the formation of completely nonmagnetic welds while suppressing solidification cracking.

The chemical composition of weld filler metals used for the welding of austenitic SSs is designed to obtain a WM with $3-8 \% \delta$-ferrite in the austenite matrix. For example, GTAW of 316L SS with conventional filler metals like ER 316L in American Welding Society (AWS) A5.9/A5.9M:2017 (ISO 14343:2009 MOD), Welding Consumables - Wire Electrodes, Strip Electrodes, Wires, and Rods for Arc Welding of Stainless and Heat Resisting Steels - Classification, ensures that the resultant WM contains some amount of $\delta$-ferrite (generally more than $3 \%$ ). The presence of ferromagnetic $\delta$-ferrite in the austenitic SS WM, although successful in alleviating the problem of hot cracking, serves to enhance $\mu_{r}$ of the weldment. Control of $\mu_{\mathrm{r}}$ of the WM is of paramount importance when considering the WM as a candidate material for components of particle accelerators. Also, while considering the application of SS helium vessels of SRF cavities, the increased $\mu_{r}$ of the WM can result in entrapment of some fraction of the earth's magnetic field and can contribute to an increase in the residual resistance of niobium materials (Refs. 33, 34). This will increase the power loss in the SRF cavities, thereby increasing the cryogenic load and increasing the operating as well as capital cost of the particle accelerators. Therefore, a reduction in the $\mu_{\mathrm{r}}$ of the austenitic SS weldment is useful for particle accelerators operating at $298 \mathrm{~K}$ as well as those operating at liquid helium temperature $(4 \mathrm{~K})$.

\section{Literature Review}

With respect to the above-mentioned requirement of low $\mu_{\mathrm{r}}$ SS welds, one such development was made and successfully implemented at the authors' laboratory (Ref. 35) during 


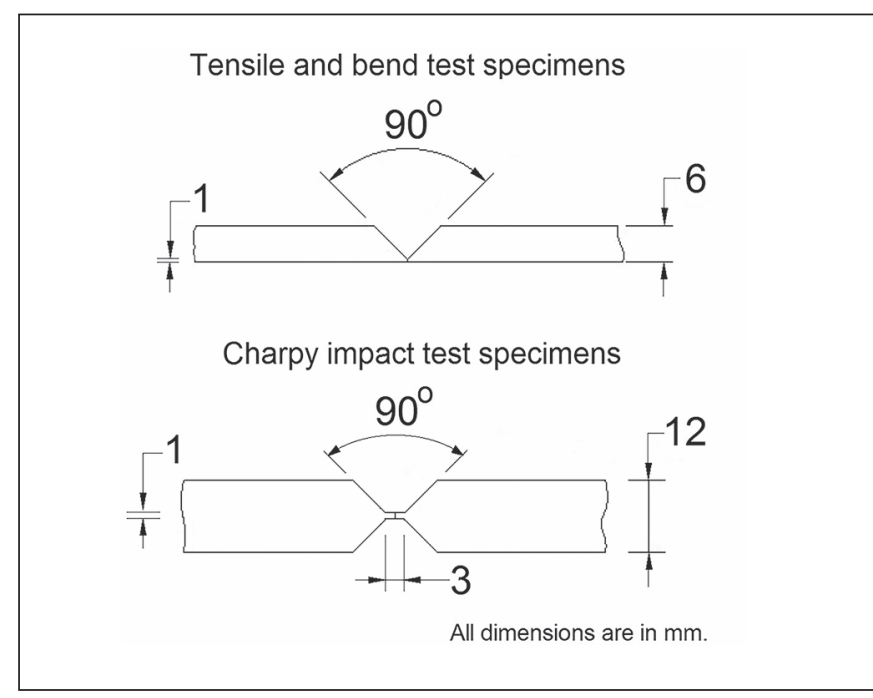

Fig. 1 - The joint designs of weld pads used for preparing tensile and impact test specimens.

the manufacturing of an injector microtron vacuum chamber (Ref. 36). This particular solution used 316LN base metal welded with high-Mn filler metal W Z18 $165 \mathrm{~N}$ L of ISO 14343. The 316LN SS base metal is not only more expensive than the conventional 316L SS, but its ready availability in all thicknesses is also a matter of concern. The filler metal is also special, scarcely available, and very expensive as compared to ER316L in AWS A5.9 (Ref. 37). The 316LN filler metal, when used for GTAW of 6-mm-thick 316L SS at the authors' laboratory, did not produce low $\mu_{\mathrm{r}}$ welds. Hence, there is a need to develop a welding process for 316L SS to obtain low $\mu_{\mathrm{r}}$ WM.

Several other nonmagnetic stainless steel grades are being used in oil well drilling sectors during directional drilling (Ref. 19). Nonmagnetism of the material is required as the magnetic field of earth is used to define the 3D position of the drilling tool as well as the drilling direction (Ref. 39). These are high-nitrogen stainless steels like $\mathrm{Cr}-\mathrm{Mn}-\mathrm{N}$ and Cr-Mo-Mn-N types (Refs. 38-40) for meeting high-strength, wear-resistant, corrosion-resistant, and nonmagnetic requirements. The relative $\mu_{\mathrm{r}}$ of these stainless steel grades and their WMs is less than 1.01 (Ref. 39). The welding of high-N stainless steel results in the loss of nitrogen from the WM, which is compensated by the addition of nitrogen in the shielding gas during GTAW (Ref. 41). The limit of nitrogen in the shielding gas is $5 \%$ to control electrode erosion and arc instability. Most of these materials are not approved by the ASME BPVC Section VIII, Division 1, for pressure vessel construction and are also not popular with particle accelerators that require an ultra-high vacuum and nonmagnetic behavior.

The limits of relative $\mu_{\mathrm{r}}$ in particle accelerators is not uniform, and they depend on application and constraints imposed by design. One $\mathrm{Cr}-\mathrm{Ni}-\mathrm{Mn}-\mathrm{N}$ stainless steel Böhler P506 (Ref. 41) was proposed for the high-energy particle accelerator Large Hadron Collider, where the relative $\mu_{\mathrm{r}}$ was restricted to be less than 1.005 at $2 \mathrm{~K}$. The welding of P506 was performed in the thickness range of 1 to $12 \mathrm{~mm}$ with a laser beam without the addition of filler metal. The weld metal exhibited a fully austenitic structure and met the re-

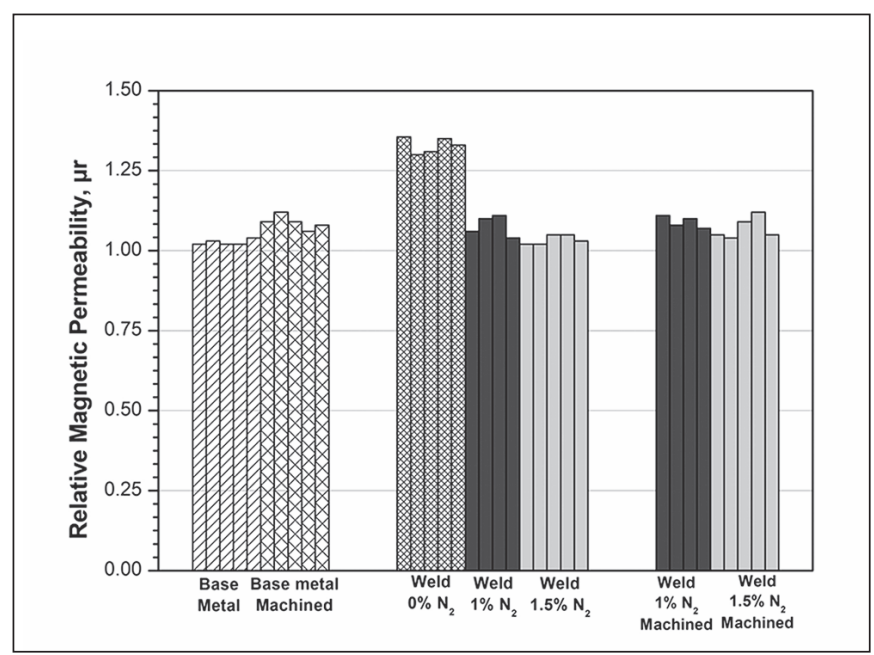

Fig. 2 - A comparison of the $\mu_{r}$ of the base metal and welded specimens (shielding gas: Ar with $0 \%, 1 \%$, and $1.5 \%$ $\mathrm{N}_{2}$ ) in as-welded and machined conditions.

quirement of relative $\mu_{\mathrm{r}}<1.005$. Commercial high-nitrogen grades and their weld metals were unable to meet this extremely stringent requirement. However, commercial stainless steel grades like 316L are also being routinely used in the construction of particle accelerators at places where the magnetic hygiene is required but either is not very stringent or is being addressed through special design and construction. Once 316L stainless steel is selected for a particle accelerator component, then the limitation of the relative $\mu_{\mathrm{r}}$ of its weld metal would be that of the base metal.

\section{Objective}

It may be noted that nitrogen is a strong austenite stabilizer; its addition to austenitic SS is known to improve corrosion resistance and cause an increase in hardness through solid solution hardening (Ref. 42). Therefore, if the GTAW process is modified to add nitrogen in the weld pool, it should serve to reduce the $\mu_{\mathrm{r}}$ of the resultant WM through the suppression of ferromagnetic $\delta$-ferrite phase formation. The upper limit of the nitrogen content of 316L SS is $0.1 \mathrm{wt}-$ $\%$ (Ref. 43), although it is usually found in the range of 0.02-0.04 wt-\%. The nitrogen-strengthened, commercially available austenitic SSs can have nitrogen content up to $0.22 \%$ by weight (steel number 1.4406 and 1.4429 in DIN EN 10028-7, Flat Products Made of Steels for Pressure Purposes - Part 7: Stainless Steels). Therefore, there is a large scope of addition of nitrogen in the WM. The possibility of adding nitrogen to the argon shielding gas to enhance the nitrogen content of the WM has been explored by other researchers. This has resulted in significant addition of nitrogen content in the WM (Refs. 44, 45). In this regard, the present experimental study was undertaken with an objective to obtain low $\mu_{r}$ GTA welds of 316L SS though controlled addition of nitrogen in the argon shielding gas. The resultant welds should not only display acceptable levels of strength and ductility but should also qualify the impact energy requirement of ASME BPVC for operation at RT and also at a cryogenic temperature of $2 \mathrm{~K}$.

Section VIII, Division 1, of the ASME BPVC 2019 edition 

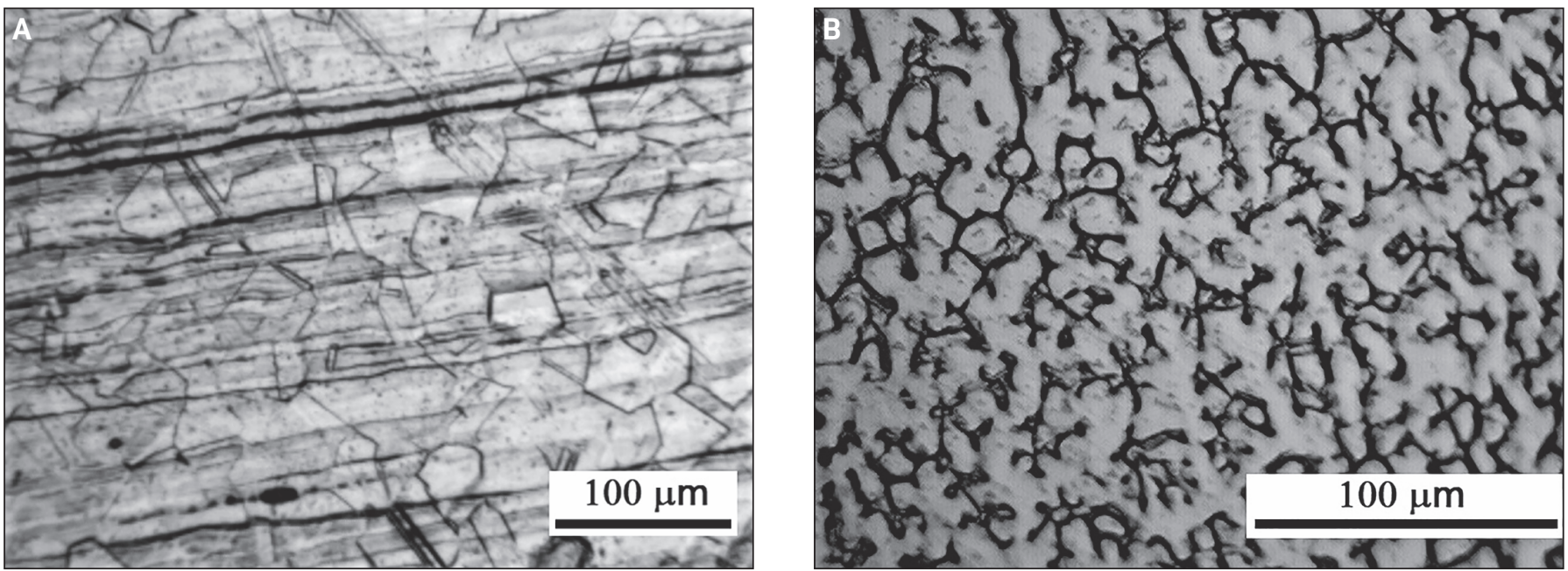

Fig. 3 - The microstructure of the 316L SS (A) base and (B) its weld metal (shielding gas: Ar).

permits the minimum design metal temperature (MDMT) to be lower than $77 \mathrm{~K}$ if the weld is qualified at $77 \mathrm{~K}$ against impact testing. Paragraph UHA - 51(a)(3)(-a) of the code allows impact testing to be performed at $77 \mathrm{~K}$, even though the MDMT is below $77 \mathrm{~K}$ under the following conditions (Ref. 46):

- Type 316L/308L filler metals are to be used;

- The welding process is to be GTAW/gas metal arc welding; and

- If 316L filler metal is used, then it shall not have a ferrite number (FN) greater than 5 , and if $308 \mathrm{~L}$ filler metal is used, it shall have a FN between 4 and 14.

Therefore, helium vessels conforming to ASME BPVC Section VIII, Division 1, can be manufactured from 316L SS, provided the welds meet the specified RT FN $(<5)$ and impact test requirements at $77 \mathrm{~K}$.

\section{Experimental Procedures}

The present experimental welding study was performed in two parts. The first part of the study was performed on 6-mmthick sheet of 316L SS, and it was aimed at optimizing the composition of the premixed shielding gas (argon + nitrogen) with respect to the $\mu_{r}, F N$, and chemical composition of the resultant WMs. On the other hand, the second part of the study was performed with optimized premixed shielding gas, and it involved characterization of the resultant WMs with respect to their chemical composition, magnetic properties, microstructure, and mechanical properties. This part of the study was performed on 6 and 12-mm-thick sheets of 316L SS. Table 1 presents the chemical composition (in wt-\%) and $\mu_{\mathrm{r}}$ of the SS sheets used for the experiments. In all of the cases, the welded SS specimens were prepared in butt configuration by manual GTAW in direct current electrode negative mode, while using a 2-mm-diameter ER 316L SS filler wire. The chemical composition of the dilution-free GTA deposit of the ER 316L filler metal is provided in Table 1 .

During GTAW, argon shielding gas was premixed with a controlled amount of nitrogen, ranging from 0 to $5 \%$ by volume. The controlled mixing of the two gases was achieved through use of a gas mixer having the capability to mix argon and nitrogen in the range of 0 to $5 \%$, with an accuracy of 0.1 $\mathrm{lit} / \mathrm{min}$. The gas mixer was comprised of two separate mass flow controllers for argon and nitrogen that control the flow rate of the respective gases, as per the user's requirement. The two gases to be mixed were individually flown into the gas mixer, and the outgoing gas mixture passed through the welding nozzle. Table 2 presents the experimental welding parameters used for the study. It may be noted that 6 -mm-thick GTA-

Table 1-Chemical Composition (wt-\%) and Magnetic Permeability $\left(\mu_{r}\right)$ of 316L SS Sheets and ER 316L Filler GTA Weld Deposit

Material

C

$\mathrm{Cr}$

$\mathrm{Ni}$

$\mathrm{Mn}$

Si

Mo

$\mathrm{Cu}$

N

S

P

$\mu_{\mathrm{r}}$

\begin{tabular}{|c|c|c|c|c|c|c|c|c|c|c|c|}
\hline $\begin{array}{l}\text { 316L SS 6-mm-thick } \\
\text { sheet }\end{array}$ & 0.03 & 16.44 & 10.04 & 2.13 & 0.237 & 2.13 & 0.33 & 0.05 & 0.0014 & 0.040 & $1.02-1.04$ \\
\hline $\begin{array}{l}\text { 316L SS 12-mm-thick } \\
\text { sheet }\end{array}$ & 0.017 & 16.83 & 10.03 & 2.10 & 0.22 & 2.10 & 0.52 & 0.039 & 0.0010 & 0.038 & $1.02-1.05$ \\
\hline $\begin{array}{c}\text { 2-mm-diameter ER } \\
\text { 316L filler }\end{array}$ & 0.0064 & 18.33 & 11.02 & 1.58 & 0.344 & 2.14 & 0.18 & 0.045 & 0.008 & 0.03 & $1.16-1.25$ \\
\hline
\end{tabular}



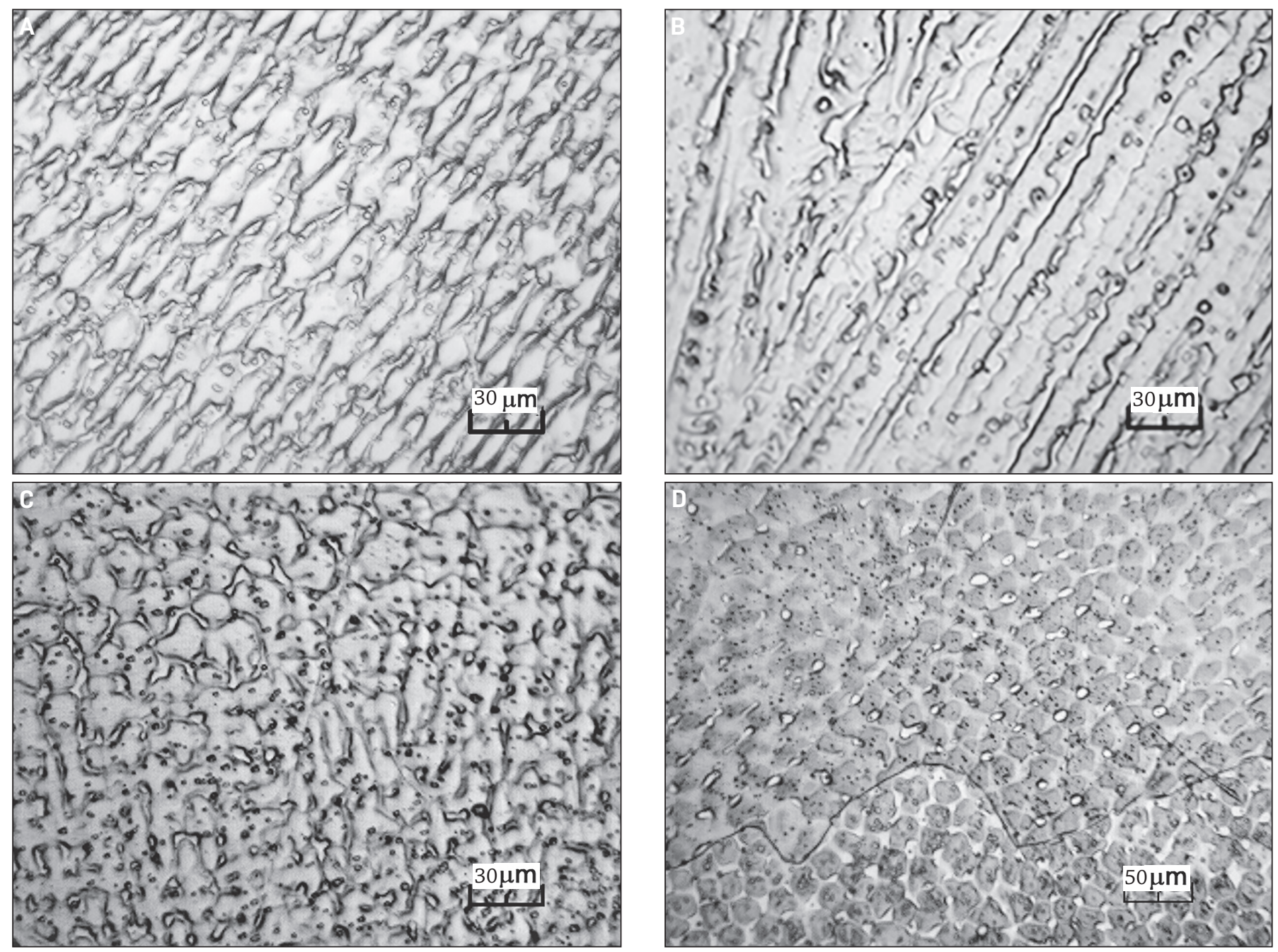

Fig. 4 - The cross-sectional microstructures of $316 \mathrm{~L}$ SS weld metals made with different premixed shielding gases. $A-A r+1 \%$ $\mathrm{N}_{2} ; \mathrm{B}-\mathrm{Ar}+1.5 \% \mathrm{~N}_{2} ; \mathrm{C}-\mathrm{Ar}+2.0 \% \mathrm{~N}_{2} ; \mathrm{D}-\mathrm{Ar}+2.5 \% \mathrm{~N}_{2}$. (Etchant: $10 \%$ oxalic acid, electrolytic etch.)

welded specimens were used for preparing tensile and bend test specimens, as per Section IX of ASME BPVC (Ref. 47), while 12-mm-thick welded specimens were used for preparing Charpy V-notch impact test specimens, as per ASTM E23, Standard Test Methods for Notched Bar Impact Testing of Metallic Materials (Ref. 48). For welding of 6-mm-thick SS sheets, a single- $\mathrm{V}$ groove was machined on the two mating edges to be welded while 12-mm-thick sheets were welded with a double-V groove joint, as shown in Fig. 1. It may be noted that the design of the welding groove for the 12-mm-thick specimens was based on the feedback obtained from an initial study where incomplete was seen at the root of the WM.

The welded SS specimens were characterized with respect to RT $\mu_{r}$, chemical composition by optical emission spectroscopy, $\delta$-ferrite number by ferritoscope, weld microstructure by optical and scanning electron microscopy, microhardness, tensile strength, ductility by guided bend test, impact strength by Charpy impact test, and low-temperature magnetic susceptibility $(\chi)$. The relative $\mu_{\mathrm{r}}$ of the base metal and weld metal was measured using a permeability meter (Ferromaster by Stefan Mayer Instruments, Germany). Measurements were carried out at RT after ensuring there was no external magnetic field interference and calibrating the measuring instrument with the standard reference $\mu=$ $1.31 \pm 0.01$ (National Physical Laboratory, UK). The permeability meter has the measuring range of 1.001 to 1.999

Table 2 - Experimental Parameters for GTAW of SS Sheets

\begin{tabular}{ccccc} 
& Voltage & Current & Welding Rate & $\begin{array}{c}\text { Composition of } \\
\text { Gas Flow Rate }\end{array}$ \\
\hline Root pass & $12-13 \mathrm{~V}$ & $75-80 \mathrm{~A}$ & $0.5-0.6 \mathrm{~mm} / \mathrm{s}$ & Nitrogen: $0-5 \%$ \\
Gas
\end{tabular}



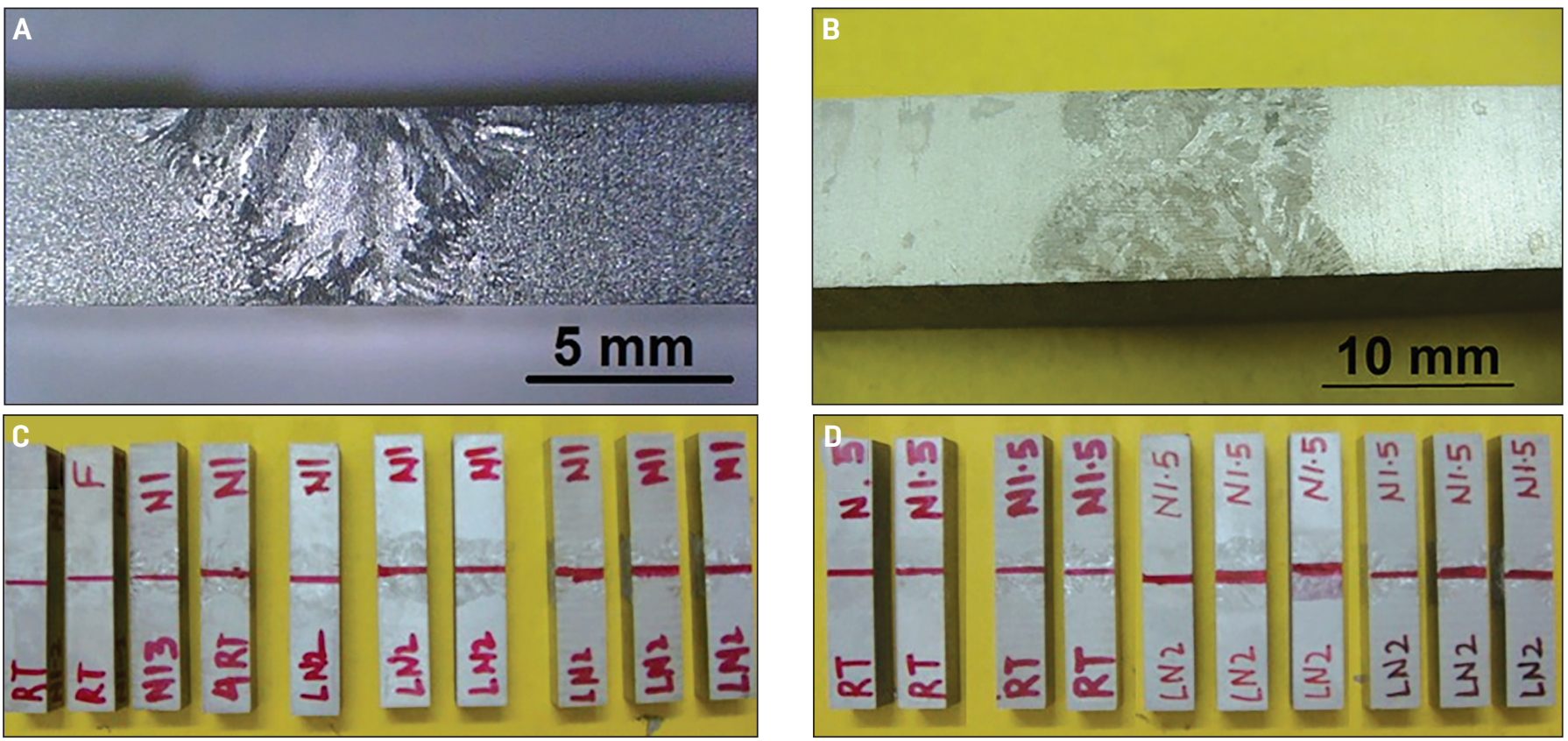

Fig. 5-A-Macrograph of the weld cross section of the 6-mm weld, flushed from top and bottom for conducting the tensile test; $B$ - macrograph of the weld cross section of the 12-mm-thick weld, machined from all sides for impact specimen fabrication; C, D - Charpy impact test specimens before machining the notch. GTA welded with (NI) $1 \%$ and (N1.5) $1.5 \%$ nitrogen premixed shielding gas, respectively. Notch machined at red lines marked at the center on weld faces/cross sections.

(resolution 0.001). $\mu_{\mathrm{r}}$ measurements were carried out on both the weld face and cross sections of the specimens at various locations prepared for impact testing (10-mm-thick double-V-groove configuration) and 6-mm-thick specimens for tensile and guided bend tests. Results of $\mu_{\mathrm{r}}$ are reported in Table 4. Magnetic susceptibility measurements were performed on cylindrical SS specimens (length: $~ 3 \mathrm{~mm}$; diameter: $\sim 3 \mathrm{~mm}$ ) extracted from the base metal and the $10-\mathrm{mm}$ thick weld metal specimens welded with $1 \%$ and $1.5 \%$ nitrogen addition in the shielding gas. The superconducting quantum interference device (SQUID) magnetometer was calibrated using a pure $\mathrm{Pd}$ reference sample with a relative permeability value of 1.0007847 . The magnetometer is extremely sensitive, and it can resolve the relative permeability up to seven decimal places. Before conducting the magnetic measurements, the specimens were electropolished to remove the cold-worked surface layer introduced by machining. The magnetization measurements as a function of temperature in a constant applied magnetic field of $\mu_{0} \mathrm{H}=2 \mathrm{mT}$ were performed in a commercial SQUID magnetometer. Three different standard protocols were adopted for the magnetization vs. temperature measurements: zero field cooled (ZFC), field-cooled cooling (FCC), and field-cooled warming (FCW). In the ZFC warming protocol, the sample was first cooled in a zero magnetic field from $300 \mathrm{~K}$ to the lowest temperature of measurement. The magnetic field was switched on at this lowest temperature, and magnetization was measured while warming up the specimen in the constant applied field. In the FCC protocol, magnetization was measured while cooling down the sample without changing the magnetic field that was applied during the ZFC protocol. After reaching the lowest temperature during the measurement in the FCC protocol, the measurement of magnetization was then performed while warming up the specimen in the presence of the same applied field, which was the FCW protocol. The temperature dependence of magnetization thus measured was used to get the temperature dependence of magnetic susceptibility as $\chi(T)=M(T) / H$. Besides magnetization vs. temperature measurements, magnetization (M) vs. magnetic field $(\mathrm{H})$ measurements were also carried out at different temperatures in the range of $10-55 \mathrm{~K} . \mathrm{M}-\mathrm{H}$ measurements were performed in the ZFC protocol.

\section{Results and Discussion}

\section{Part I of the Study}

Table 3 presents the results of the $\mu_{r}, F N$, and nitrogen content of the experimental GTA welds. It may be noted that the $\mu_{\mathrm{r}}$ and FN data reported in this table is the range of values obtained or average of five and eight measurements, respectively. It was seen that with an increase in the nitrogen content of the premixed shielding gas, the resultant SS welds experienced a corresponding reduction in their $\mu_{\mathrm{r}}$ and FN. The initial addition of nitrogen in the argon shielding gas brought about an abrupt reduction in $\mu_{\mathrm{r}}$ and FN of the WM, while further increasing the nitrogen reduced the rate of reduction in $\mu_{\mathrm{r}}$ and $\mathrm{FN}$, and beyond $3 \% \mathrm{~N}_{2}$ in the shielding gas, a further drop in these two parameters was quite low. It should be noted that the $\mu_{\mathrm{r}}$ of 316L SS base metal was found to be in the range of 1.02-1.05; therefore, there is little advantage in obtaining SS WM with a $\mu_{\mathrm{r}}$ less than 1.05 . SS welds with a $\mu_{\mathrm{r}}$ of 1.05 produced with $2 \%$ nitrogen addition in the Ar shielding gas introduced up to $0.28 \%$ nitrogen (max.) in the WM. With the above considerations, it was felt that $\mathrm{Ar}$ shielding gas with a nitrogen content of $1-1.5 \%$ should give rise to the WM with an acceptable level of $\mu_{\mathrm{r}}$ and FN (welds with FN $<5$ can be impact tested at $77 \mathrm{~K}$ for MDMT of $2 \mathrm{~K}$ [Ref. 42]). 
Table 3 - Results of Magnetic Permeability $\left(\mu_{\mathrm{r}}\right)$, Ferrite Number (FN), and Nitrogen Content of Experimental GTA Weld Metals (6 mm thick) Made with Different Compositions of Shielding Gas ( $\left.\mathrm{Ar}+\mathrm{N}_{2}\right)$

\begin{tabular}{cccc}
$\begin{array}{c}\text { Composition of Shielding Gas } \\
\text { (vol-\%) }\end{array}$ & $\mu_{\mathrm{r}}$ & FN & $\begin{array}{c}\text { Nitrogen Concentration } \\
\text { (wt-\%) }\end{array}$ \\
\hline $100 \% \mathrm{Ar}$ & $1.2-1.3$ & 4.53 & 0.04 \\
$99 \% \mathrm{Ar}+1 \% \mathrm{~N}_{2}$ & $1.09-1.129$ & $0.9-1.9$ & $0.11-0.16$ \\
$98.5 \% \mathrm{Ar}+1.5 \% \mathrm{~N}_{2}$ & $1.04-1.08$ & $0.2-2.2$ & $0.15-0.2$ \\
$98 \% \mathrm{Ar}+2 \% \mathrm{~N}_{2}$ & 1.056 & 0.9 & $0.17-0.28$ \\
$97 \% \mathrm{Ar}+3 \% \mathrm{~N}_{2}$ & 1.028 & 0.21 & $0.19-0.22$ \\
$96 \% \mathrm{Ar}+4 \% \mathrm{~N}_{2}$ & 1.020 & 0.12 & $0.16-0.28$ \\
$95 \% \mathrm{Ar}+5 \% \mathrm{~N}_{2}$ & 1.011 & 0.11 & $0.25-0.40$ \\
\hline
\end{tabular}

Table 4-Results of Relative Magnetic Permeability $\left(\mu_{\mathrm{r}}\right)$ and Ferrite Number (FN) Measurements on 316L SS Welds Made with Argon Shielding Gas Containing 1 and $1.5 \%$ Nitrogen

Weld Thickness $\quad \begin{gathered}\text { Composition of } \\ \text { Shielding Gas (vol-\%) }\end{gathered}$

$99 \% \mathrm{Ar}+1 \% \mathrm{~N}_{2}$

$12 \mathrm{~mm}$ : Double-V groove

$6 \mathrm{~mm}$ : Single-V groove

$99 \% \mathrm{Ar}+1 \% \mathrm{~N}_{2}$

$98.5 \% \mathrm{Ar}+1.5 \% \mathrm{~N}_{2}$

$98.5 \% \mathrm{Ar}+1.5 \% \mathrm{~N}_{2}$ $\mu_{\mathrm{r}}$ (Average)

FN

As Welded Welded + Machined

$\begin{array}{lll}1.06 & 1.07 & 1.0-1.14\end{array}$

1.098

1.11

1.4-1.8

1.02

1.05

$0.22-0.29$

1.03

1.05

0.14-0.28

1.07

1.09

$0.56-0.78$

1.17

1.23

$1.76-1.78$

1.16

1.24

1.06

1.055

0.29-2.07

1.07

1.057

\section{Part II of the Study}

\section{Magnetic Permeability and FN Measurements}

In this part of the study, 6- and 12-mm-thick SS welds were made with premixed shielding gas of 1 and $1.5 \%$ nitrogen (by volume) while also using 316L SS filler wire for melting the root pass. The $\mu_{\mathrm{r}}$ and FN measurements of the resultant weldments are presented in Table 4 . The results show that in all the welds made with $1.5 \%$ nitrogen, the $\mu_{\mathrm{r}}$ was less than 1.1 (often close to 1.05). Figure 2 compares the $\mu_{\mathrm{r}}$ of 12 -mm-thick 316L SS GTA WM (made with a premixed shielding gas of 1 and $1.5 \%$ nitrogen content) with that of the base metal. It was also seen that machining of GTA welds (made with premixed shielding gas) did not cause any significant increase in their $\mu_{\mathrm{r}}$.

\section{Chemical Compositional Analysis}

Table 5 presents the chemical composition (as determined by optical emission spectroscopy), $\mu_{\mathrm{r}}$, and FN of 316L SS welds made with shielding gas containing 1 and $1.5 \%$ nitrogen. The results demonstrate that the addition of nitrogen in the argon shielding gas serves to increase the nitrogen content of the WM, which results in the suppression of the related FN and $\mu_{\mathrm{r}}$. In the case of both 6and 12 -mm-thick 316L SS sheets, the addition of $1.5 \%$ nitrogen in the argon shielding gas produced a WM with a $\mu_{\mathrm{r}}$ (1.033-1.035) quite close to the base metal, while the addition of $1 \%$ nitrogen in the shielding gas produced a WM with a relatively higher value of $\mu_{r}(1.07-1.17)$. 


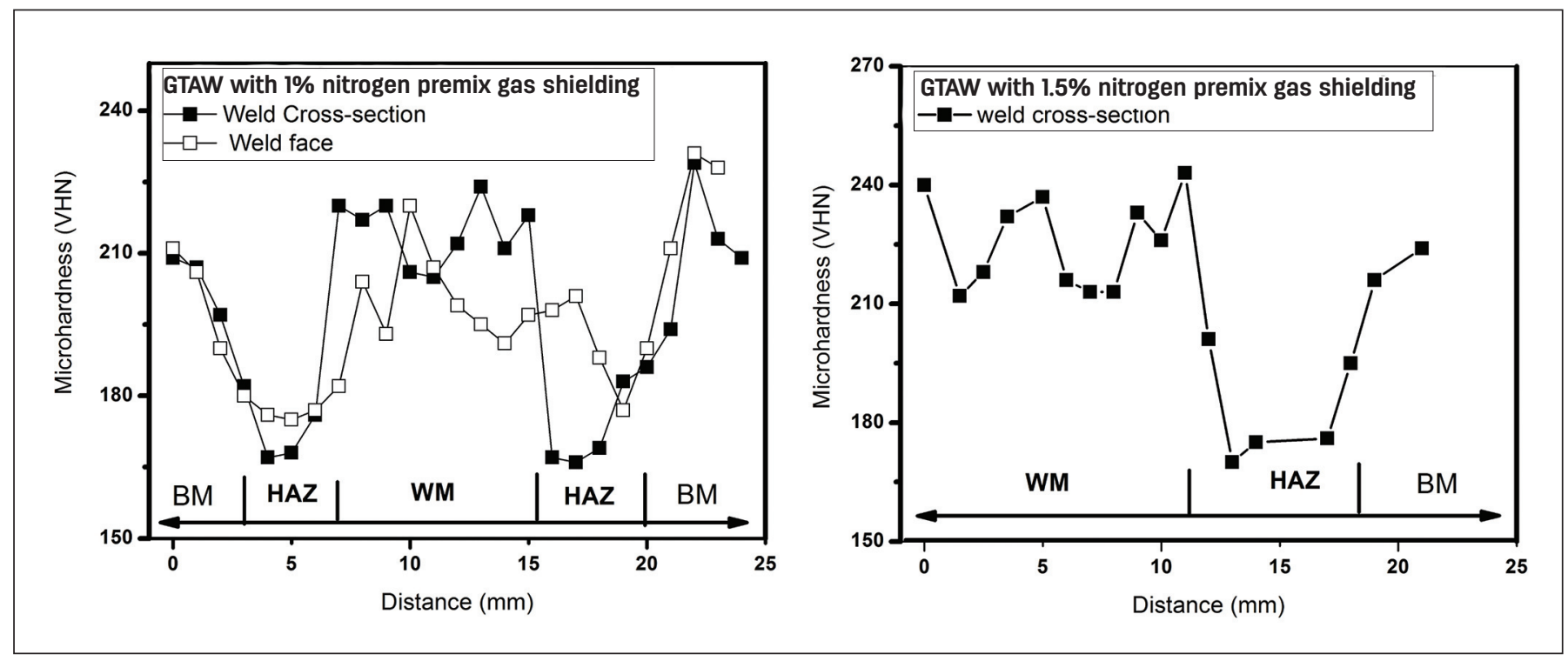

Fig. 6 - Microhardness profiles across the welds made with a premixed shielding gas of 1 and $1.5 \%$ nitrogen.

\section{Microstructural Characterization and Microhardness Measurements}

A metallographic examination of the cross sections of the base metal and welds of 6- and 12-mm-thick specimens of 316L SS was carried out. Type 316L SS base metal in the asreceived (mill-annealed) condition displayed typical banded structure with equiaxed austenite grains. Figure 3A presents the microstructure of the SS base metal in the as-received condition. The metallographic examination of the 316L SS WM (with Ar shielding gas without nitrogen addition) displayed a significant presence of $\delta$-ferrite in the microstructure $(\mathrm{FN}=4.53$, Table 5$)$. The vermicular morphology of the retained $\delta$-ferrite at the dendrite core shown in Fig. 3B is indicative of a primary ferrite mode of solidification (Refs. 9, 49). Due to the presence of a large amount of $\delta$-ferrite, the
GTA welds made with argon shielding gas also displayed a $\mu_{\mathrm{r}}$ of 1.2-1.3. The measurements performed on the face, root, and cross section of the welds yielded similar results. The controlled addition of $1-1.5 \%$ nitrogen in the argon shielding gas brought about a significant modification in the WM microstructure. The appearance of retained $\delta$-ferrite was significantly reduced as compared to welds made without nitrogen addition, with a drop in corresponding FN and $\mu_{r}$ values. Further increasing the nitrogen content of the shielding gas beyond $1.5 \%$ by volume further reduced the $\mu_{\mathrm{r}}$ values (Ref. Table 3). Increasing the nitrogen beyond $1.5 \%$ has no additional advantage as the $\mu_{\mathrm{r}}$ value of the WM $\left(1.5 \% \mathrm{~N}_{2}\right)$ is close to that of the base metal $\left(\mu_{\mathrm{r}}=1.05\right)$. The WM $(1-1.5 \%$ $\mathrm{N}_{2}$ premixed shielding gas) displayed predominantly primary austenite cells/dendrites indicating the primary austenite mode of solidification in the WM. Figure 4 presents microstructures of 316L SS WMs made with 1 to $2.5 \%$

\begin{tabular}{|c|c|c|c|c|c|c|c|c|c|c|c|}
\hline Weld Specimen & C & $\mathrm{Cr}$ & $\mathrm{Ni}$ & $\mathrm{Mn}$ & Si & Mo & $\mathrm{N}$ & S & $\mathrm{P}$ & $\mu_{\mathrm{r}}$ & FN \\
\hline $\begin{array}{l}\text { Thickness: } 6 \mathrm{~mm} \\
\text { Shielding gas: } \mathrm{Ar}\end{array}$ & 0.026 & 17.67 & 10.01 & 1.43 & 0.27 & 2.01 & 0.045 & 0.0056 & 0.021 & 1.27 & 4.53 \\
\hline $\begin{array}{l}\text { Thickness: } 6 \mathrm{~mm} \\
\text { Shielding gas: } \\
98.5 \% \mathrm{Ar}+1.5 \% \mathrm{~N}_{2}\end{array}$ & 0.024 & 17.78 & 10.93 & 1.57 & 0.32 & 2.08 & 0.146 & 0.0071 & 0.027 & 1.035 & 0.22 \\
\hline $\begin{array}{c}\text { Thickness: } 12 \mathrm{~mm} \\
\text { Shielding gas: } 99 \% \\
\qquad \mathrm{Ar}+1 \% \mathrm{~N}_{2}\end{array}$ & 0.012 & 18.15 & 10.79 & 1.51 & 0.29 & 2.10 & $0.12-0.14$ & 0.0069 & 0.034 & 1.07 & 0.78 \\
\hline
\end{tabular}




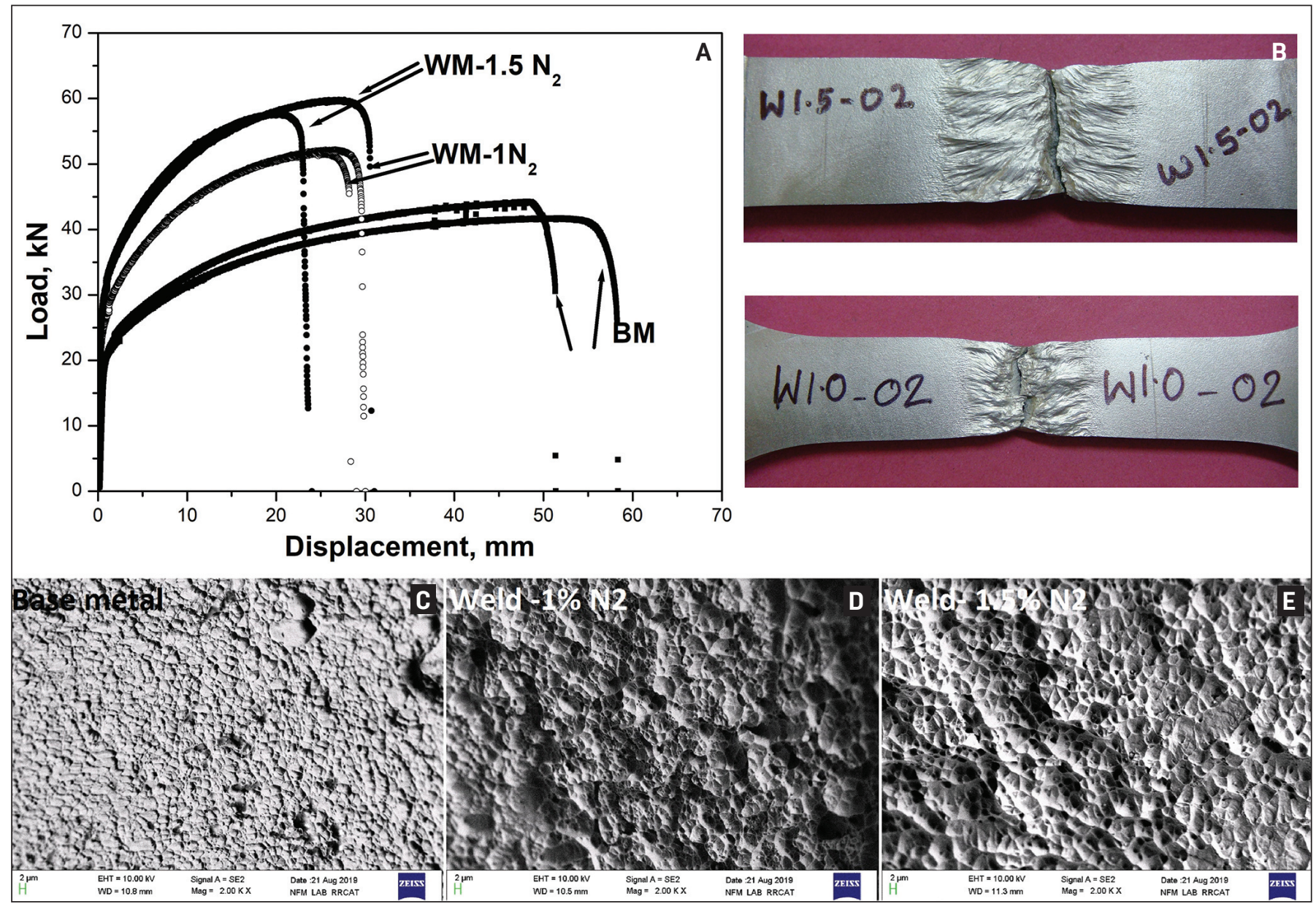

Fig. $7-$ A - Tensile load-displacement data; B - photos of failure locations of welded specimens; $C$ - fractograph of tensiletested 316L SS base metal; D - fractograph of GTA-welded specimen with premixed shielding gas $A r+1 \% N_{2}\left(W 1.0 / W M-1 N_{2}\right)$; $E-$ fractograph of GTA-welded specimen with premixed shielding gas $\mathrm{Ar}+1.5 \% \mathrm{~N}_{2}\left(\mathrm{~W} 1.5 / \mathrm{WM}-1.5 \mathrm{~N}_{2}\right)$.

nitrogen addition in the argon shielding gas. Figure $5 \mathrm{~A}$ and B presents the macrographs of the weld cross sections of 6mm- and 12-mm-thick welds. The figures show the etched cross sections of machined tensile and impact specimens depicting the weld metal in the full thickness.

\section{Microhardness Measurements}

Microhardness measurements were carried out using a Vickers microhardness tester using a load of $200 \mathrm{~g}(1.96 \mathrm{~N})$ on the weld face and cross sections of the 6- and 12-mmthick welded specimens. The microhardness of the $6-\mathrm{mm}-$ thick 316L SS base metal was in the range of 200-210 VHN. Microhardness profiles across the welds made with a premixed shielding gas of 1 and $1.5 \%$ nitrogen are shown in Fig. 6. The WMs with Ar shielding gas with 1 and $1.5 \%$ nitrogen displayed microhardness values in the range of 200-225 and 195-230 VHN, respectively. In both cases, the microhardness of the HAZ of the welds was in the range of 160-170 VHN.

\section{Tensile and Bend Testing of GTA Weldments at RT}

GTA-welded 316L SS specimens, made with premixed shielding gases of $99 \% \mathrm{Ar}+1 \% \mathrm{~N}_{2}$ and $98.5 \% \mathrm{Ar}+1.5 \% \mathrm{~N}_{2}$, displayed tensile strength in the range of 552-572 $\mathrm{MPa}$, which is comparable to that of the base metal. Both kinds of welded specimens exhibited ductile fractures in the WM with a percentage reduction in area ranging from 44.8 to $58.9 \%$. The welded specimens exhibited 52-55\% elongation in $25-\mathrm{mm}$ gauge length, and the base metal exhibited about $69-72 \%$ elongation in 50-mm gauge length. Tensile loaddisplacement data, photos of failure locations of the welded specimens, and fractographs of the tensile-tested 316L SS base metal are presented in Fig. 7. Apparently, the higher peak load with respect to the base metal in the case of the welded specimens is due to different cross-section dimensions. Base metal specimens were prepared as per ASTM E8, Standard Test Methods for Tension Testing of Metallic Materials, and welded specimens were prepared as per ASME BPVC Section IX. Weld metal specimens of 1 and $1.5 \%$ nitrogen were of different thicknesses due to machining to flush out the weld metal and remove the distortion. High-magnification examination of the fracture surfaces of the tensile-tested base metal and welded specimens exhibited dimpled fracture surfaces, representing the ductile nature of fracture, as shown in Fig. 7.

Guided bend ductility tests were performed on the 6- 

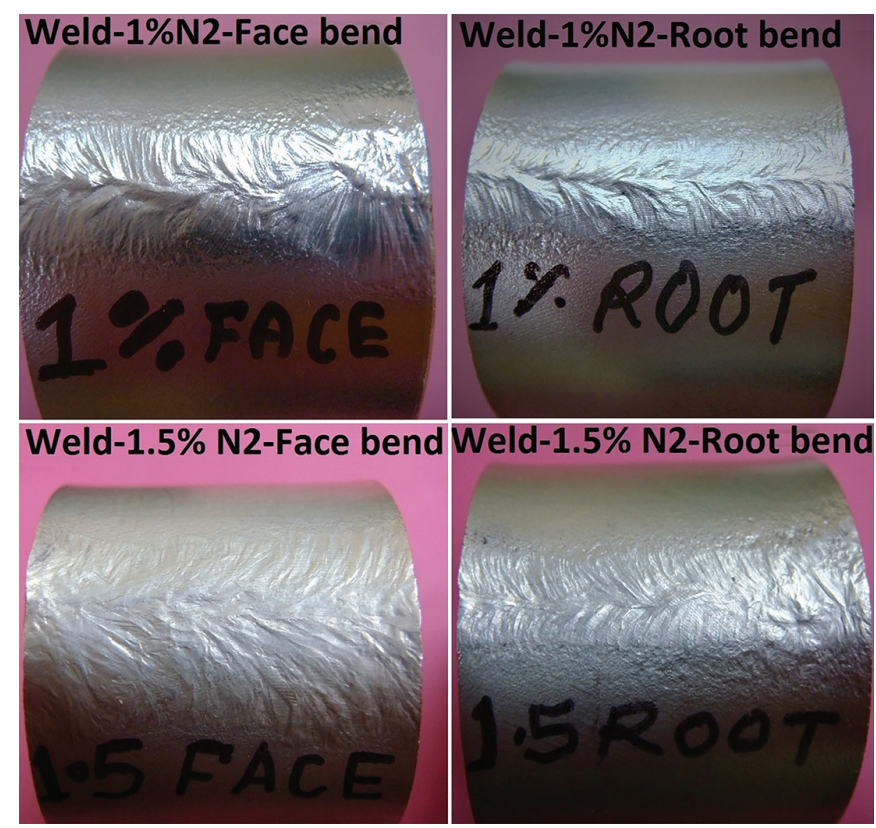

Fig. 8 - Convex surfaces of guided-bend-tested GTA-welded (made with a premixed shielding gas of 1 and $1.5 \%$ nitrogen) specimens.

mm-thick base metal and its welded specimens (made with a premixed shielding gas of $99 \% \mathrm{Ar}+1 \% \mathrm{~N}_{2}$ and $98.5 \% \mathrm{Ar}+$ $\left.1.5 \% \mathrm{~N}_{2}\right)$. Welded specimens $(150 \times 150 \times 6 \mathrm{~mm})$ were machined on face and root sides to flush out excess weld metal. Specimens that were $150 \times 38 \times 5 \mathrm{~mm}$ were extracted from the central portion of the weldments, excluding about 25 $\mathrm{mm}$ at either edge. Transverse face bend and root bend tests were carried out, as per the test procedures in ASME BPVC Section IX, QW 160 and QW 462.3(a) (Ref. 47). The test jig used for conducting the guided bend tests was prepared, as per WQ 466.1. The thickness of the plunger (bend die diameter) was $20 \mathrm{~mm}$, which was four times the specimen's thickness $(\mathrm{T}=5 \mathrm{~mm})$. The specimen was placed on greased adjustable shoulders with a gap of $6 \mathrm{~T}+3.2 \mathrm{~mm}(\sim 33.2 \mathrm{~mm})$, as per the test standard. The specimens were bent to a U shape with the weld face/root facing downward by applying a load using a $150-\mathrm{kN}$ universal testing machine in the stroke control mode slowly without any jerking. In the case

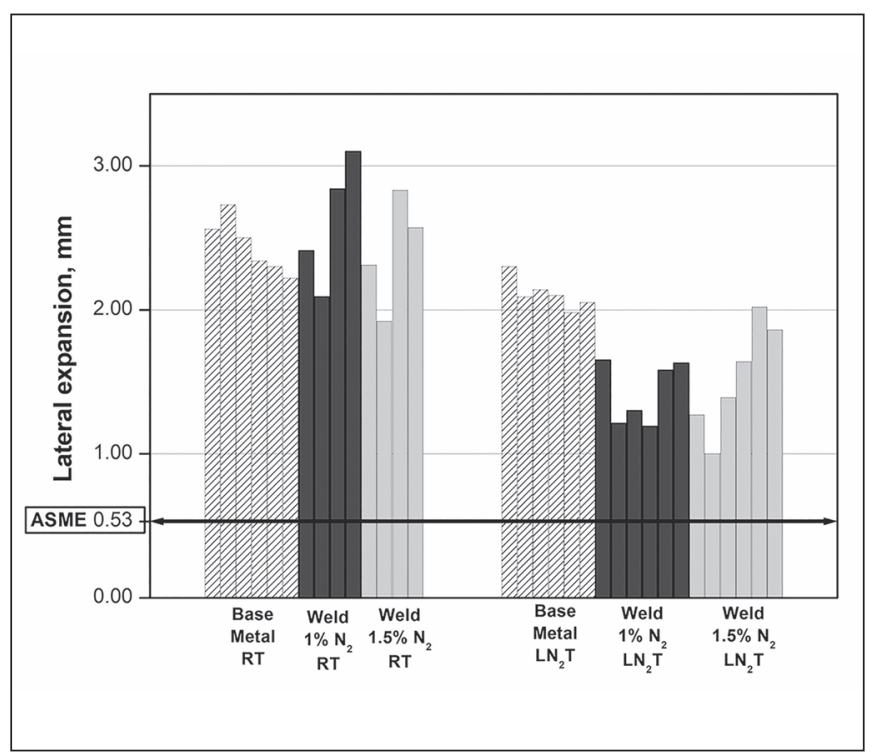

Fig. 9 - Comparison of lateral expansion of the Charpyimpact-tested base metal and GTA-welded 316L SS specimens with respect to the minimum qualifying value specified by the ASME BPVC. RT: room temperature, $L N_{2} T$ : liquid nitrogen temperature.

of the welded specimens, the tests were conducted in transverse face bend and transverse root bend configurations. None of the bent specimens developed any cracks on their convex surface. Figure 8 presents photographs of guidedbend-tested GTA-welded specimens of 316L SS.

\section{Impact Testing of GTA Weldments}

The 12-mm-thick welded specimens $(100 \times 100 \times 12$ $\mathrm{mm}$ ) were machined on both sides to flush out the excess weld metal. The machined specimens (10-mm-thick weldments) were used to extract the Charpy test specimens $(10 \times$ $10 \times 55 \mathrm{~mm}$ ) by wire electro-discharge machining. The specimens were etched to reveal the macrostructure of the weld to identify the weld face and cross section. A Charpy V notch was made on the weld face for some specimens and on the weld cross section for other specimens. Figure $5 C$ and D presents the photos of the Charpy test specimens before

Table 6 - Results of Charpy Impact Tests of 316L SS Specimens

\begin{tabular}{|c|c|c|c|c|}
\hline Specimen & Test Temperature & Notch Details & Impact Energy (J) & Remarks \\
\hline & Room temperature & - & $254-296$ & Specimens not broken \\
\hline Base metal & $\mathrm{LN}_{2}$ temperature & - & $212-248$ & Specimens not broken \\
\hline \multirow{2}{*}{$\begin{array}{l}\text { Weld metal } \\
\text { Shielding gas: } \\
1 \% \mathrm{~N}_{2}+99 \% \mathrm{Ar}\end{array}$} & Room temperature & Notch on weld cross section & 274 and 286 & Specimens not broken \\
\hline & $\mathrm{LN}_{2}$ temperature & Notch on weld face & $144,124,118$ & - \\
\hline \multirow{3}{*}{$\begin{array}{l}\text { Weld metal } \\
\text { Shielding gas: } \\
1.5 \% \mathrm{~N}_{2}+99 \% \mathrm{Ar}\end{array}$} & Room temperature & Notch on weld cross section & 296 and 276 & Specimens not broken \\
\hline & \multirow[t]{2}{*}{$\mathrm{LN}_{2}$ temperature } & Notch on weld face & 114, 134, 130 & - \\
\hline & & Notch on weld cross section & $122,146,154$ & - \\
\hline
\end{tabular}




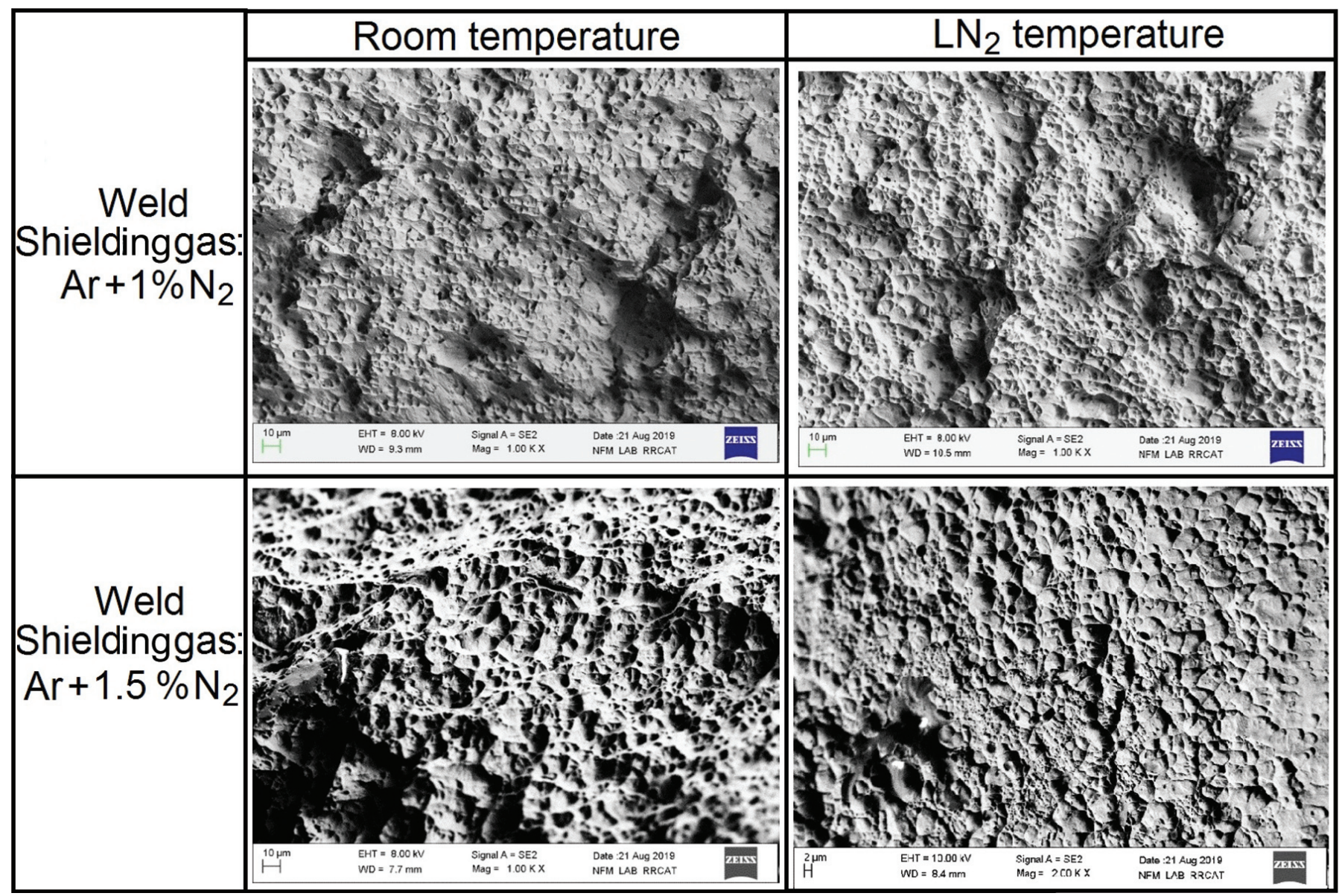

Fig. 10 - Magnified views of the fracture surface of impact-tested GTA-welded 316L SS specimens (made with a premixed shielding gas of 1 and $1.5 \%$ nitrogen) at $R T$ and $L N_{2} T$.

making notches. Two-mm-deep notches were machined using a notch cutter exclusively meant for preparing notches on Charpy impact specimens. Standard Charpy V-notch impact specimens, extracted from the base metal and GTAwelded specimens (made with premixed $\mathrm{Ar}+\mathrm{N}_{2}$ shielding gas with nitrogen content of 1 and $1.5 \%$ ), were tested at RT $(298 \mathrm{~K})$ and at liquid nitrogen temperature $\left(\mathrm{LN}_{2} \mathrm{~T}\right.$ : $\left.77 \mathrm{~K}\right)$, as per the ASTM E23 testing procedure. The results of the Charpy impact tests are presented in Table 6. It can be seen that specimens with a notch on the weld cross section absorbed higher energy for failure with respect to specimens with a notch on the weld face for both the specimens welded with 1 and $1.5 \% \mathrm{~N}_{2}$ in the shielding gas. Charpy impact specimens, tested at RT as well as at $\mathrm{LN}_{2}$ temperature, displayed prominent shear lip regions separated by a narrow, flat region. Lateral expansion values associated with Charpy-impact-tested specimens are presented in Fig. 9. Fractographic examination of the Charpy-tested base metal and welded specimens under a scanning electron microscope revealed ductile fractures associated with dimples of mixed size, as shown in Fig. 10.

According to UHA-51(a)(3)(-a)(-3) of the ASME BPVC, Section VIII, Division 1, 2019 edition, the Charpy V-notch impact-tested specimens should display a minimum lateral expansion of $0.53 \mathrm{~mm}$ if the MDMT is less than $-196^{\circ} \mathrm{C}$. This lateral expansion corresponds to the impact energy of $\sim$
$53 \mathrm{~J}$ (impact energy in $\mathrm{J} \approx$ lateral expansion in $\mathrm{mm} \times 100$ ) (Ref. 50). For the welded specimens, the values of lateral expansion of Charpy-tested specimens at RT were close to that of the base metal specimens. In the case of weld specimens tested at liquid nitrogen temperature, the lateral expansion values were well above the ASME requirement of $0.53 \mathrm{~mm}$, with corresponding Charpy impact energy values in the range of 114-154 J. The specified minimum Charpy impact energy for 316L SS for flat stainless steel products for pressure purposes as per DIN EN 10028-7 is 100 and $60 \mathrm{~J}$ at 293 $\mathrm{K}(\mathrm{RT})$ and $77 \mathrm{~K}\left(\mathrm{LN}_{2} \mathrm{~T}\right)$, respectively (Ref. 51). The results of the Charpy impact tests presented in Table 6 show that the impact energy of GTA WM made with premixed shielding gas $\left(\mathrm{Ar}+\mathrm{N}_{2}\right)$ was much higher than the minimum requirements of the SS 316L base metal as per DIN EN 10028-7 standard at both $\mathrm{RT}$ and $\mathrm{LN}_{2} \mathrm{~T}$.

\section{Magnetic Susceptibility Measurements}

Temperature-dependent magnetic susceptibility measurements were performed on specimens extracted from a 12-mm-thick base metal and its GTA WM made with argon shielding gas with $0,1.0$ and $1.5 \%$ nitrogen. The test results are presented in Fig. 11 . It can be seen that the $\chi$-T plot of the base metal is similar to reported results for austenitic SSs. The magnetic susceptibility peak at about $40 \mathrm{~K}$ is gener- 

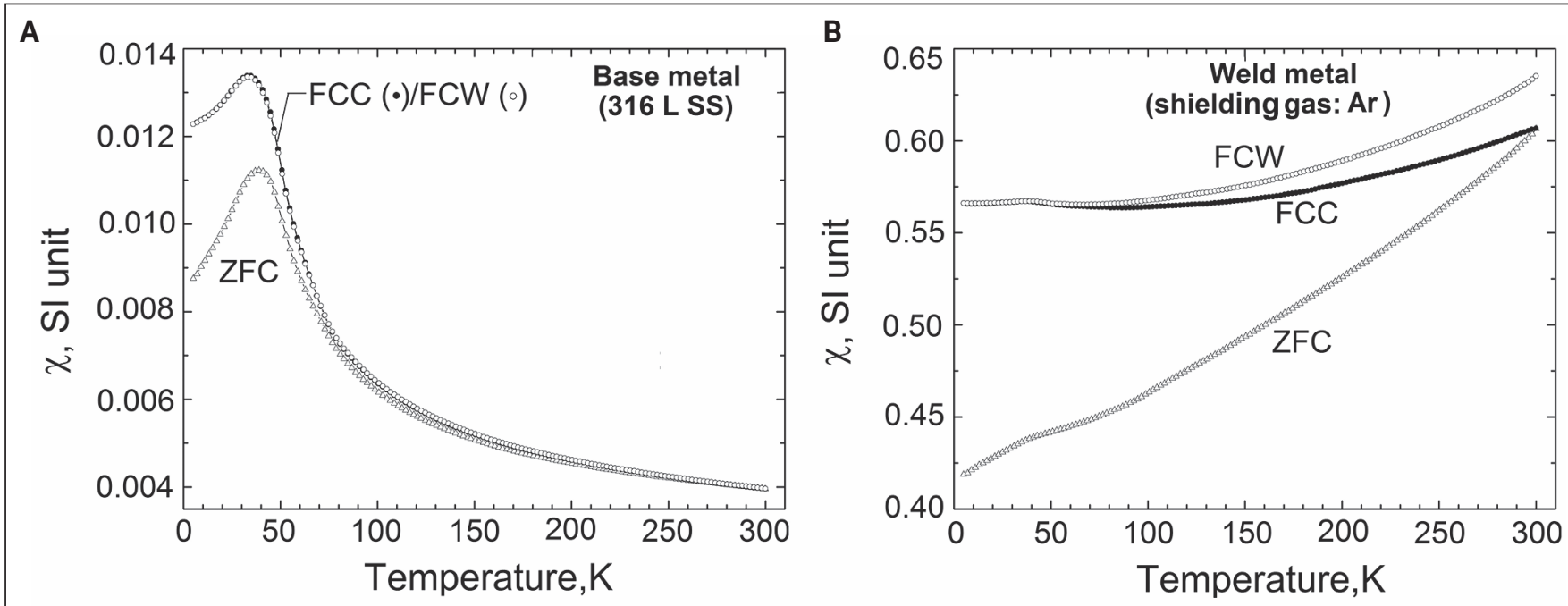

C
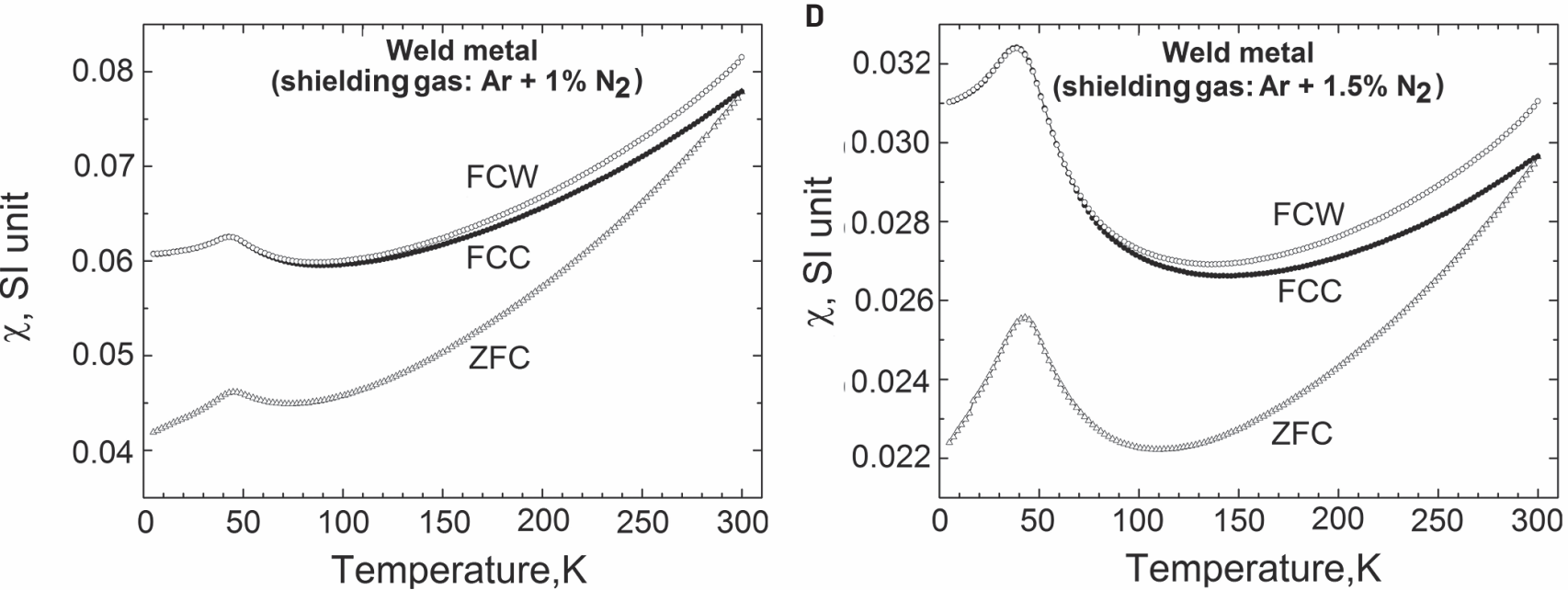

Fig. 11 - Magnetic susceptibility $(\chi)$ vs. temperature plots of 316L SS (12-mm-thick base metal) (A) and GTA weld metals made with a shielding gas of argon (B), argon $+1 \%$ nitrogen $(C)$, and argon $+1.5 \%$ nitrogen (D).

ally attributed to paramagnetic-antiferromagnetic transition (Ref. 52). However, the irreversibility between the ZFC and FCC plots until high temperatures indicates that the respective phases may not be purely paramagnetic or antiferromagnetic. Further studies are required to gain insight into the exact nature of the magnetic phases with a possibility of underlying short-range correlations, which is beyond the scope the present study. The M-H plot of the base metal specimens at different temperatures in supposedly paramagnetic and antiferromagnetic phases displayed a nearly linear behavior, as shown in Fig. 12A. The measurements recorded a maximum value of magnetization at $40 \mathrm{~K}$, which is in line with the magnetic susceptibility results presented in Fig. 11A. Whereas the $\chi$-T plot of the GTA WM made with argon shielding gas (Fig. 11B) displayed an entirely different behavior. In contrast to the base metal specimen, the GTA WM specimen exhibited a continuous increase/decrease in magnetic susceptibility during warming/cooling (Fig. 12A) without any peak in susceptibility. Instead, the $\chi$-T plots of the WM displayed a change in slope at $40 \mathrm{~K}$ in all three protocols of measurement. The magnitude of magnetic susceptibility of the GTA WM specimen was significantly higher than that of the base metal specimen. It is believed that the magnetic response of the GTA WM was largely dominated by that of the ferromagnetic $\delta$-ferrite phase present in the WM. The rise in magnetic susceptibility with a rise in temperature during ZFC measurements is generally observed in the case of ferromagnets at temperatures well below the Curie temperature. These results therefore indicate the presence of a magnetically ordered phase whose Curie temperature was much greater than the RT. The M-H plots of the WM specimens at 30-50 K show a tendency toward saturation at a higher field (Fig. 12B), which also reflects the dominating response of the ferromagnetic $\delta$-ferrite phase present in the WM. The addition of $1 \%$ nitrogen in the shielding gas brought about a noticeable change in the magnetic response of the WM specimen. A notable difference produced by the $1 \%$ addition of nitrogen gas in the $\chi$-T plot of the WM specimen included the reappearance of a low-temperature peak at $40 \mathrm{~K}$ and the relative reduction in magnetic susceptibility - Fig. 11C. The M-H plots of the WM specimens (with $1 \% \mathrm{~N}_{2}$ in the shielding gas) at $35-55 \mathrm{~K}$ also showed a tendency toward saturation at a high field, although with a relative reduction in the magnetization with respect to that of the WM made without nitrogen addition in 

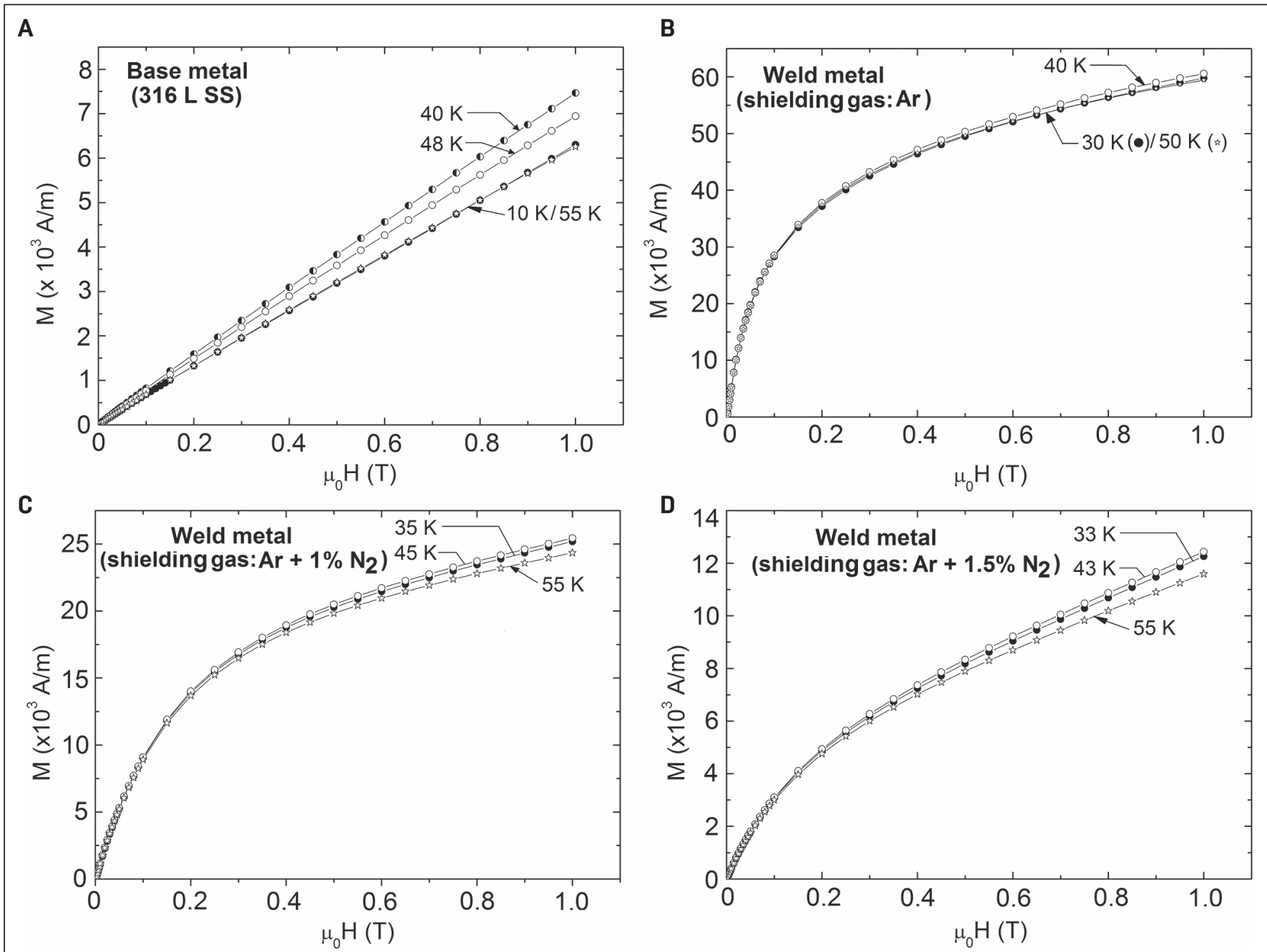

Fig. $12-\mathrm{M}-\mathrm{H}$ plots of $316 \mathrm{~L}$ SS (12-mm-thick base metal) (A) and GTA weld metals made with a shielding gas of argon (B), argon $+1 \%$ nitrogen $(C)$, and argon $+1.5 \%$ nitrogen $(D)$.

the argon shielding gas - Fig. 12C. The results reflect a more visible effect of the paramagnetic austenite phase, although the contribution of the ferromagnetic $\delta$-ferrite phase to the overall response of the specimen was still significantly high. Further increase in nitrogen addition in the shielding gas resulted in further reduction of magnetic susceptibility, while displaying a more prominent low-temperature peak in the $\chi$-T plot of the WM specimen - Fig. 11D. The magnetic response of the WM indicates that most of the paramagnetic austenite phase was retained. A small amount of $\delta$-ferrite in the WM still made a significant contribution to its overall magnetic response, which is also reflected in its M-H plot - Fig. 12D. A notable feature of the magnetic susceptibility plot of the GTA WM specimen is the large difference in magnetic susceptibility values of the material at cryogenic temperatures tested under ZFC and FCC/FCW protocols. This irreversibility indicates that the effect of a stray magnetic field on the net magnetic response of the material is history dependent, which underlines the importance of shielding the materials from earth's magnetic field. The difference between the ZFC and FCC/FCW plots gradually narrows down as the nitrogen content in the shielding gas was enhanced. At a temperature of $5 \mathrm{~K}$, the dif- ference in the magnetic susceptibility of the specimen measured under ZFC and FCC protocols was 0.009 with respect to the corresponding value of 0.003 for the 316L SS base metal. Both the dimensionless quantities of volumetric magnetic susceptibility $(\chi)$ and relative $\mu_{\mathrm{r}}$ are empirically related $(1+\chi=$ $\mu_{\mathrm{r}}$ ) (Ref. 52). It may be noted that the RT $\mu_{\mathrm{r}}$ values corresponding to the magnetic susceptibility $(\chi)$ measurements (Fig. 11: $\chi$ values corresponding to $\mathrm{RT} \sim 300 \mathrm{~K}$ for various specimens) using the above relation were well within the range of $\mu_{\mathrm{r}}$ of respective specimens measured by a permeability meter. The above observation confirms the reliability of RT $\mu_{r}$ values obtained by a magnetic permeability meter, which is more conservative. These results show that the addition of nitrogen gas in the argon shielding gas serves to increase the austenitic phase in the resultant WM to a large extent.

\section{Conclusion}

The results of the study have demonstrated that the $\mu_{\mathrm{r}}$ of multipass GTA-welded 316L stainless steel can be effectively reduced through the controlled addition of nitrogen in the argon shielding gas while using conventional ER316L stain- 
less steel filler metal.

For $1.5 \%$ nitrogen addition by volume in the argon shielding gas, nitrogen concentration in the resultant multipass weld metal increased from about $0.04 \mathrm{wt}-\%$ to $0.15-0.2$ wt- $\%$. The resultant weld metal exhibited magnetic permeability ( $\left.\mu_{\mathrm{r}}: 1.033-1.035\right)$ quite close to that of the base metal $\left(\mu_{\mathrm{r}}: 1.02-1.05\right)$. There was a significant reduction in the FN value from 4.53 (WM without nitrogen) to about 0.22-0.59 for the WM with a $1.5 \%$ nitrogen addition in the argon shielding gas. This shows the direct relationship between $\mu_{\mathrm{r}}$ and FN values, as both are a manifestation of the WM's $\delta$ ferrite content, which is controlled through nitrogen alloying of the WM.

The welded specimens not only displayed good ductility and RT strength close to that of the base metal but also qualified the Charpy impact test requirement as specified by the ASME BPVC for operation at RT as well as at the liquid helium temperature of $4 \mathrm{~K}$.

Although the magnetic susceptibility of the WM (made with $98.5 \% \mathrm{Ar}+1.5 \% \mathrm{~N}_{2}$ shielding gas) was of the same order of magnitude as that of the base metal, it displayed significant thermomagnetic irreversibility. Therefore, any cooldown of the welded 316L stainless steel vessel should be carried out in a magnetically shielded environment to reduce the effect of the trapped field.

The technique developed in this study is highly useful for the fabrication of BPVC-compliant 316L SS vacuum chambers and pressure vessels for particle accelerators, including helium vessels of superconducting RF cavities.

\section{Acknowledgment}

The authors are thankful to A. M. Puntambekar for many useful discussions during the course of the study. They are also thankful to Vinit Lal for preparing welding coupons for the study. They thankfully acknowledge the help of D. C. Nagpure and Abhijit Chowdhury in the preparation of samples for welding and their subsequent mechanical testing. They also thank Honey Gupta, a project trainee, for conducting hardness testing and microscopy, and Ram Nihal Ram for preparing the specimens for metallographic examination.

\section{References}

1. Mathers, G. 2002. The Welding of Aluminum and Its Alloys, $1^{\text {st }}$ edition. Cambridge, England: Woodhead Publishing, pp. 10-31.

2. The Lincoln Electric Co. 1994. The Procedure Handbook of Arc Welding, pp. 9.1-1 to 9.4-12.

3. Doshi, S. J., Gohil, A. V., Mehta, N. D., and Vaghasiya, S. R. 2018. Challenges in fusion welding of $\mathrm{Al}$ alloy for body in white. Materials Today: Proceedings 5: 6370-6375. DOI: 10.1016/ j.matpr.2017.12.247

4. Mandal, N. R. 2002. Aluminium Welding. Cambridge, England: Woodhead Publishing, pp. 10-21.

5. Armao, F. 2001. Preparing for aluminium GTAW. Retrieved October 3, 2020 from thefabricator.com/article/aluminumwelding/ preparing-for-aluminum-gtaw.

6. Bauer, W. 1980. Fabrication of niobium cavities. Proceedings of SRF Workshop, pp. 271-288.

7. C-Therm Technologies. What is coefficient of thermal expansion (CTE)? How do I measure it? Retrieved January 9, 2020 from ctherm.com/resources/newsroom/blog/coefficient-of-thermalexpansion/.

8. Theilacker, J., Carter, H., Foley, M., Hurh, P., Klebaner, A., Krempetz K., Nicol, T., Olis, D., Page, T., Peterson, T., Pfund, P., Pushka, D., Schmittand, R., and Wands, R. 2010. Guidelines for the design, fabrication, testing, installation and operation of SRF cavities. AIP Conference Proceedings 1218: 1223-1230. DOI: 10.1063/ 1.3422289

9. Lacombe, P., Baroux, B., and Beranger, G., eds. 1993. Stainless Steels. Les Ulis, Cedex A, France: Les Editions de Physique, pp. 593-611, 695-731.

10. McGuire, M. F. 2008. Stainless Steels for Design Engineers. Materials Park, Ohio: ASM International, pp. 69-78.

11. Davis, J. R., ed. 2006. Corrosion of Weldments. Materials Park, Ohio: ASM International, pp. 1-10.

12. Borland, J. C., and Youngar, R. N. 1960. Some aspects of cracking in welded $\mathrm{Cr}-\mathrm{Ni}$ austenitic steels. British Welding Journal 7(1): 22 to 59 .

13. Hull, F. C. 1967. Effect of delta ferrite on the hot cracking of stainless steel. Welding Journal 46(9): 399-s to 409-s.

14. Matsuda J. F., Nakaagawa, H., Uehara, T., Katayama, S., and Arata, Y. 1979. A new explanation for role of $\delta$-ferrite improving weld solidification crack susceptibility and amount of phosphide and sulphide in SUS 310 weld metal. Trans. Jpn. Weld. Res. Inst. 8: 105-112.

15. Hull, F. C. 1967. The effect of $\delta$-ferrite on the hot cracking of stainless steel. Welding Journal 46(9): 399-s to 409-s.

16. Pellini, W. S. 1952. Strain theory of hot tearing. Foundry 80: 125-199.

17. Thier, H., Killing, R., and Killing, U. 1987. Solidification modes of weldments in corrosion resistant steels - How to make them visible. Metallurgical Constr. 19: 127-132.

18. Schaffler, A. L. 1942. Constitution diagram for stainless steel weld metal. Metal Progress 56: 680-680B.

19. Delong, W. T., Ostrom, G., and Szumachowskim, E. 1956. Measurment and calculation of ferrite in stainless steel weld metal. Welding Journal 36(11): 521-s to 528-s.

20. DeLong, W. T. 1974. Ferrite in austenitic stainless steel weld metal. Welding Journal 53(7): 273-s to 286-s.

21. Siewert, T. A., McCowan, C. N., and Olson, D. L. 1988. Ferrite number prediction to $100 \mathrm{FN}$ in stainless steel weld metal. Welding Journal 67(12): 289-s to 298-s.

22. Kotecki, D. J., and Siewert, T. A. 1992. WRC-1992 Constitution diagram for stainless steel weld metals: A modification of the WRC-1988 diagram. Welding Journal 71(5): 171-s to 178-s.

23. Masumoto, I., Takami, K., and Kutsuna, M. 1972. Hot cracking of austenitic stainless steel weld metal. Japan Welding Society 41: 1306-1314.

24. Oates, W. R., and Saitta, A. M., eds. 1998. Materials and applications - Part 2. Welding Handbook, Vol. 4, $8^{\text {th }}$ edition. Miami, Fla: American Welding Society.

25. Kujanpaa, V., Suutala, N., Takalo, T., and Moisio, T. 1979. Correlation between solidification cracking and microstructure in austenitic-ferritic stainless steel welds. Welding Research International 9(2): 55-76.

26. Araki ,Y., Sano, H., Kominami, M., and Oikawa, H. 1982. Study on $\mathrm{Cr}-\mathrm{Ni}$ austenitic filler metal containing Mn. Trans. Jap. Weld. Soc. 13: 32-40.

27. Kujanapa, V. P. 1985. Effects of steel type and impurities in solidification cracking of austenitic stainless steel welds. Metal Construction 17: 40R-46R.

28. Dixon, B. F. 1989. Control of magnetic permeability and solidification cracking in welded non-magnetic steel. Welding Journal 68(5): 171-s to 180 -s. 
29. Hull, F. C. 1960. Effects of alloying additions on hot cracking of austenitic stainless steels. Proceedings of $63^{\text {rd }}$ Annual Meeting of ASTM, 667-690. West Conshohocken, Penn.: ASTM.

30. Matsuda, F., Nakagawa, H., Katayama, S., and Arata, Y. 1982. Solidification crack susceptibility in weld metal of fully austenitic stainless steels (Report VII) - Effect of Mn and N on solidification crack resistance. Trans. JWRI 11: 79-85.

31. Dixon, B. F. 1988. Weld metal solidification cracking in austenitic stainless steels. Australian Welding Research 16: 2-10.

32. Kane, S. F., Farland, A. L., Siewert, T. A., and McCowan, C. N. 1999. Welding consumable development for a cryogenic (4K) application. Welding Journal 78(8): 292-s to 300-s. DOI: 10.1007/ 978-1-4757-9056-6_12

33. Chandrasekaran, S. K., Grassellino, A., Grimm, C., and Wu, G. 2016. Magnetic field management in LCLS-II $1.3 \mathrm{GHz}$ cryomodules. Proc. LINAC2016, 527-530. Geneva, Switzerland: Joint Accelerator Conferences Website.

34. McGee, M. W., Chandrasekaran, S. K., Crawford, A. C., Harms, E., Leibfritz, J., and Wu, G. 2016. Cryomodule test stand reduced-magnetic support design at FERMI Lab. $7^{\text {th }}$ International Particle Accelerator Conference. Geneva, Switzerland: Joint Accelerator Conferences Website.

35. Kumar, A., Soni, R. K., Ganesh, P., Kaul, R., Bhatnagar, V. K., Dwivedi, J., and Kukreja, L. M. 2014. A study on low magnetic permeability gas tungsten arc weldment of AISI 316LN stainless steel for application in electron accelerator. Materials \& Design 53: 86-92.

36. Dutta, S., and Dwivedi, J. 2017. Development, testing and integration of new $20 \mathrm{MeV}$ injector microtron. RRCAT Newsletter 30(2).

37. A5.9/A5.9M-2006, Specification of Bare Stainless Steel Welding Electrodes and Rods. Miami, Fla.: American Welding Society.

38. Saller, G., and Aigner, H. 2004. High nitrogen alloyed steels for nonmagnetic drill collars. Standard steel grades and latest developments. Materials and Manufacturing Processes 19(1): 41-49. DOI: 10.1081/AMP-120027497

39. Deutsche Edelstahlwerke, Nonmagnetic stainless steels Magnadur. Retrieved December 18, 2020, from dew-stahl.com/ fileadmin/files/dew-stahl.com/documents/Publikationen/Broschueren/ 2016-0060_DEW_Magnadur_GB.pdf.

40. Gooch, T. G. 2000. Welding new stainless steels for the oil and gas industry. Retrieved December 18, 2020, from twiglobal.com/technical-knowledge/published-papers/welding-newstainless-steels-for-the-oil-and-gas-industry-march-2000.

41. Sgobba, S., and Hochoertler, G. 1999. A new non-magnetic stainless steel for very low temperature. Proceedings of International Congress in Stainless Steel, pp. 391-401. Milan, Italy: Associazione Italiana di Metallurgia.

42. Simmon, J. W. 1996. Overview: High-nitrogen alloying of stainless steels. Materials Science and Engineering A 27(2): 159-169.
43. ASTM A240/A240M-2019, Standard Specification for Chromium and Chromium-Nickel Stainless Steel Plate, Sheet, and Strip for Pressure Vessels and for General Applications. West Conshohocken, Penn: ASTM International. DOI: A0240_A0240M-20A

44. Tseng, K. H., and Chou, C. P. 2003. The study of nitrogen in argon gas on the angular distortion of austenitic stainless steel weldments. Journal of Materials Processing Technology 142: 139-144.

45. Nage, D. D., and Raja, V. S. 2006. Effect of nitrogen addition on the microstructure and mechanical behavior of $317 \mathrm{~L}$ and $904 \mathrm{~L}$ austenitic stainless steel welds. Journal of Materials Science 41: 2097-2112.

46. Bonnemaa, E. C., Cunninghama, E. K., and Rumela, J. D. 2014. Design and fabrication considerations for stainless steel liquid helium jackets surrounding SCRF cavities. Proc. AIP Conf. 1573 827-833.

47. ASME Boiler \& Pressure Vessel Code Section IX 2015. QW150, QW 161, QW-462. New York, N.Y.: The American Society of Mechanical Engineers.

48. ASTM E23-2018, Standard Test Methods for Notched Bar Impact Testing of Metallic Materials. West Conshohocken, Penn: ASTM International. DOI: 10.1520/E0023-18

49. Shankar, V., Gill, T. P. S., Mannan, S. L., and Sundaresan, S. 2003. Solidification cracking in austenitic stainless steel welds. Sadhana 28: 359-382.

50. TWI Global, Charpy impact energy/lateral expansion for stainless steel. Retrieved December 19, 2020, from twi-global.com/ technical-knowledge/faqs/faq-what-is-the-relationship-betweencharpy-impact-energy-and-charpy-lateral-expansion-for-austeniticstainless-steels-and-duple.

51. DIN EN10028-7: 2016, Flat Products Made of Steels for Pressure Purposes - Part 7: Stainless Steels, pp. 19-23. Berlin, Germany: Deutsches Institut für Normung.

52. Sgobba, S. 2011. Physics and measurements of magnetic materials. Accessed June 3, 2020, from arxiv.org/ftp/arxiv/papers/ 1103/1103.1069.pdf.

\begin{abstract}
ABHAY KUMAR, PUPPALA GANESH (ganesh@rrcat.gov.in), VISHNU KUMAR SHARMA, MEGHMALHAR MANEKAR, RAM KISHOR GUPTA, RASHMI SINGH, MRIGYENDRA KUMAR SINGH, GIRDHAR MUNDRA, and RAKESH KAUL are with the Raja Ramanna Centre for Advanced Technology, Indore, Madhya Pradesh, India. SHARMA is also with the Homi Bhabha National Institute, Training School Complex, Anushakti Nagar, Mumbai, India.
\end{abstract}

